Fakultas Sains dan Teknologi - Universitas Kanjuruhan Malang

\title{
PENERAPAN AUGMENTED REALITY SEBAGAI PEMBELAJARAN KONEKSI JARINGAN
}

\author{
Roni Wibowo ${ }^{1}$, Rudi Hariyanto ${ }^{2}$, Anang Aris Widodo ${ }^{3}$ \\ Fakultas Teknologi Informasi, Universitas Merdeka Pasuruan ${ }^{1,2,3}$ \\ roni.wibow@gmail.com ${ }^{1}$, rudihariy4nt0@gmail.com², anangariswidodo@gmail.com ${ }^{3}$
}

\begin{abstract}
Abstrak. Penggunaan teknologi saat ini sudah mampu memvisualisasikan sebuah tindakan di kehidupan nyata menjadi sebuah objek dalam sebuah aplikasi. Augmented Reality adalah sebuah teknologi yang menggabungkan dunia nyata dengan dunia virtual yang bersifat interaktif dan realtime. Pengembangan Augmented Reality sebagai media pembelajaran pun juga sedang berkembang. Namun pada saat ini materi pembelajaran tentang teknik informasi dan komunikasi telah dihapuskan dari kurikulum pembelajaran siswa, hal ini sangat mempengaruhi kebutuhan siswa tentang komputer dan jaringan. Siswa yang terlanjur mengetahui informasi dasar mengenai jaringan pun tidak bisa mempraktikkan langsung ilmunya dan mengkoneksikan koneksi jaringan. Dari permasalahan tersebut terbentuklah sebuah media pembelajaran koneksi jaringan yang berjudul "Penerapan AR Sebagai Pembelajaran Koneksi Jaringan" yang berguna untuk menampilkan objek 2 dimensi menjadi objek 3 dimensi serta koneksi dalam mengatur jaringan komputer dan tes koneksi jaringan komputer.
\end{abstract}

Kata Kunci: Augmented Reality, Koneksi Jaringan.

\section{PENDAHULUAN}

Di era globalisasi ini teknologi informasi mengalami kemajuan yang sangat pesat, dimana peran penting dari teknologi informasi tersebut sangat berguna bagi kehidupan masyarakat. Penggunaan teknologi dalam kehidupan sehari-hari dapat membantu menyelesaikan beberapa pekerjaan seperti mengolah data, mencatat agenda sehari-hari, bertatap muka melalui video conference, dan bahkan saat ini sudah mampu memvisualisasikan sebuah tindakan di kehidupan nyata menjadi sebuah objek dalam sebuah aplikasi.

Teknologi yang mampu memvisualisasikan dan menggabungkan dunia nyata dengan virtual tersebut salah satunya adalah teknologi Augmented Reality. AR atau Augmented Reality adalah sebuah teknologi yang menggabungkan dunia nyata dengan dunia virtual yang bersifat interaktif dan realtime (Azuma, 1997). Augmented Reality bertujuan untuk mengambil dunia nyata sebagai dasar dengan menggabungkan beberapa teknologi virtual agar pemahaman manusia sebagai penggunanya semakin jelas. Fungsi dari Augmented Reality ini adalah meninggatkan anggapan seseorang dari dunia yang ada disekitarnya menjadi dunia virtual yang mampu memberikan informasi yang akurat dan membantu dalam bidang pendidikan, kesehatan, pelatihan, permainan dan lain sebagainya.

Seiring dengan berkembangnya teknologi dan perubahan-perubahan dunia yang kompleks, menuntut manusia untuk selalu menyegarkan kembali kemampuan yang dimilikinya sesuai dengan kapasitas perubahan tersebut. Pada dasarnya manusia memiliki potensi dasar yang idealnya akan terus berkembang apabila diasah secara terus menerus. Pembelajaran yang menyenangkan dan interaktif sangat dibutuhkan dalam membantu menyegarkan kembali kemampuan dan menambah kemampuan itu sendiri.

Pada saat ini materi pembelajaran tentang teknik informasi dan komunikasi telah dihapuskan dari kurikulum pembelajaran siswa. Hal ini sangat mempengaruhi kebutuhan siswa akan informasi dan edukasi mengenai komputer beserta jaringannya. Pembelajaran mengenai pengenalan jaringan dan koneksi jaringan pun pada akhirnya tidak lagi digunakan. Siswa yang selama ini diberikan ilmu mengenai pengenalan jaringan hanya akan mengetahui informasi dasar mengenai jaringan tanpa mengetahui bagaimana mempraktikkan dan menkoneksikan jaringan.

Pengembangan media pembelajaran berbasis Augmented Reality untuk pengenalan perangkat jaringan komputer (Sigit, dkk. 2016) membantu me-review materi sebesar $40 \%$ yang telah diajarkan oleh guru, serta membantu untuk memvisualisasikan cara kerja topologi jaringan 
komputer sebesar 45\%, dan secara keseluruhan aplikasi ini sangat sesuai dengan materi komputer dan jaringan.

Menurut penelitian yang dilakukan oleh Zainuddin, Zahir dkk(2016) aplikasi AR pada sistem informasi bangunan mampu memproyeksikan objek 3D bangunan dengan jarak terbaik antara perangkat mobile ke marker adalah $40 \mathrm{~cm}-50 \mathrm{~cm}$.

Dari apa sudah penulis ketahui dari beberapa penelitian sebelumnya, Penerapan Augmented Reality hanya berpaku pada bagaimana merendering objek dari 2 dimensi menjadi sebuah objek 3 dimensi dan menampilkan informasi umum mengenai spesifikasi dari objek yang sudah ditampilkan. Skripsi ini mengangkat permasalahan mengenai manfaat Augmented Reality dalam membatu memberikan pembelajaran koneksi jaringan pada pengaturan IP Address dan tes koneksi agar mempermudah dalam mempelajari koneksi jaringan itu sendiri.

\section{METODE PENELITIAN}

Berikut dijelaskan kerangka kerja dalam pembuatan aplikasi ini. Kerangka yang akan dilakukan melalui beberapa tahapan antara lain:

1. Perancangan Sistem.

Sebelum aplikasi dibuat harus diketahui terlebih dahulu bagaimana aplikasi akan dibuat beserta alur berjalannya aplikasi.

2. Antar Muka Pengguna

Antarmuka Pemakai (User Interface) merupakan mekanisme komunikasi antara pengguna (user) dengan sistem. Antarmuka pemakai (User Interface) dapat menerima informasi dari pengguna (user) dan memberikan informasi kepada pengguna (user) untuk membantu mengarahkan alur penelusuran masalah sampai ditemukan suatu solusi.

3. Penyiapan Resouce

Penyiapan resource meliputi segala bentuk file yang mendukung pembuatan aplikasi. Diantaranya vufora, unity file assets, dan lain sebagainya.

4. Pengkodean

Setelah semua resource dan lay-out dibuat, tahapan selanjutnya adalah melakukan konfigurasi dan pengkodean program.

5. Uji Coba Aplikasi dan Evaluasi

Setelah pemrograman selesai dilakukan dan aplikasi sudah dapat dijalankan di device target, maka yang harus dilakukan selanjutnya adalah pengujian. Uji coba yang dilakukan dengan cara menjalankan aplikasi ini kemudian dievaluasi jika terdapat kesalahan-kesalahan yang harus diperbaiki.

Dalam pembuatan aplikasi berbasis Augmented Reality ini menggunakan berbagai macam hardware dan software, diantaranya:

1. Perangkat Keras (Hardware)

Perangkat keras yang akan digunakan dalam pembuatan aplikasi ini adalah:

Tabel 1. Perangkat Keras

\begin{tabular}{ll}
\hline Platform & Laptop Lenovo ideapad 330 \\
\hline Processor & AMD A9-9425 RADEON R5, 5 \\
& $\begin{array}{l}\text { COMPUTE CORES 2c+3G } \\
\text { (2CPUs), -3.1 GHz }\end{array}$ \\
\hline Hard Drive / Memory & 1000GB / 8GB \\
\hline Operating System & Microsoft Windows 10 Pro 64 bit \\
\hline Platform & Smartphone Realmi 5i \\
\hline Processor & Snapdragon 665 \\
\hline Operating System & Android 10.0 Q \\
\hline Main Camera & 12 MP \\
\hline Memory & 4 GB \\
\hline
\end{tabular}


2. Flowchart Sistem

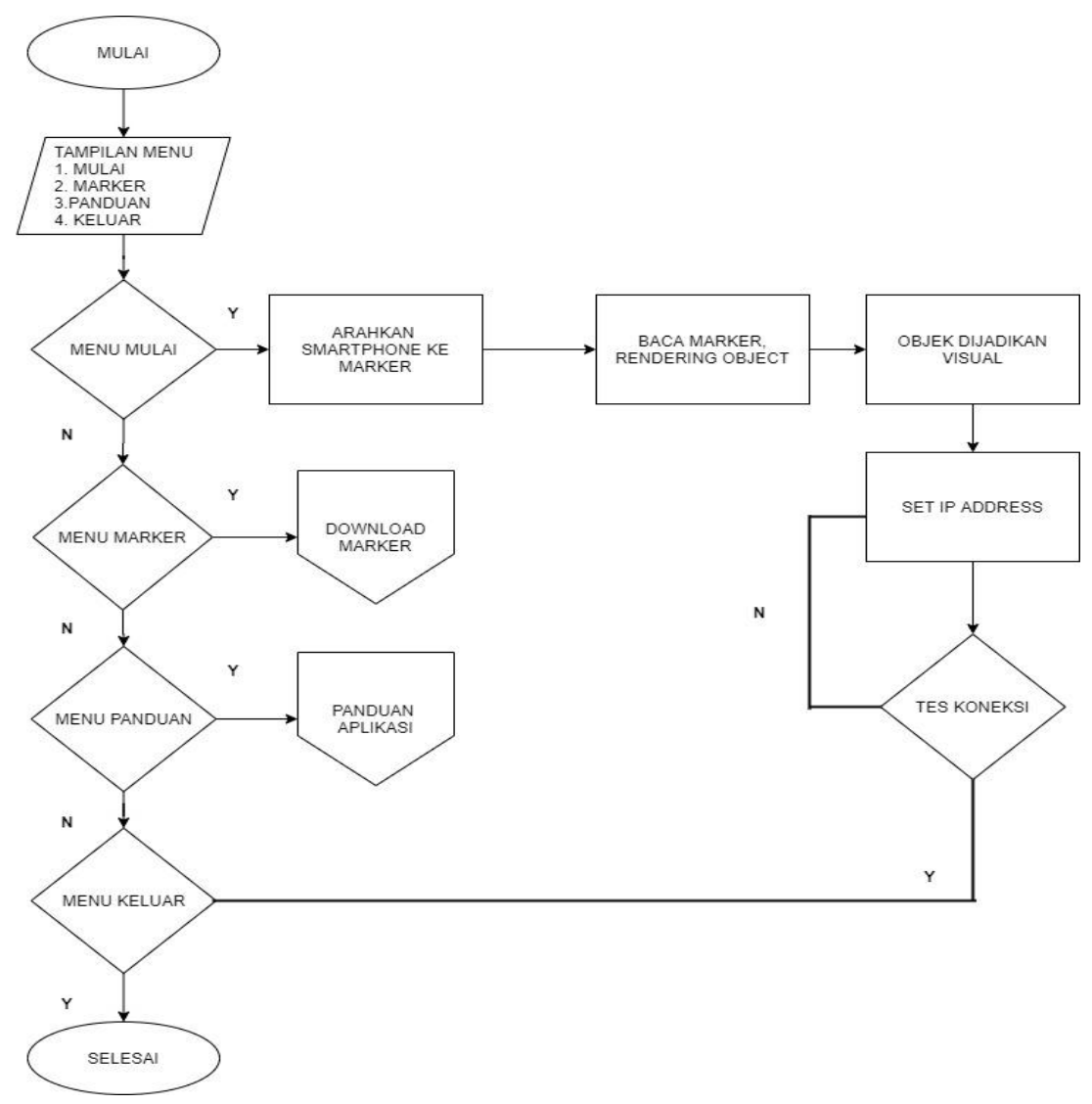

Gambar 1. Flowchart Sistem

3. Perancangan Antarmuka

Tabel 2. Perancangan Antarmuka

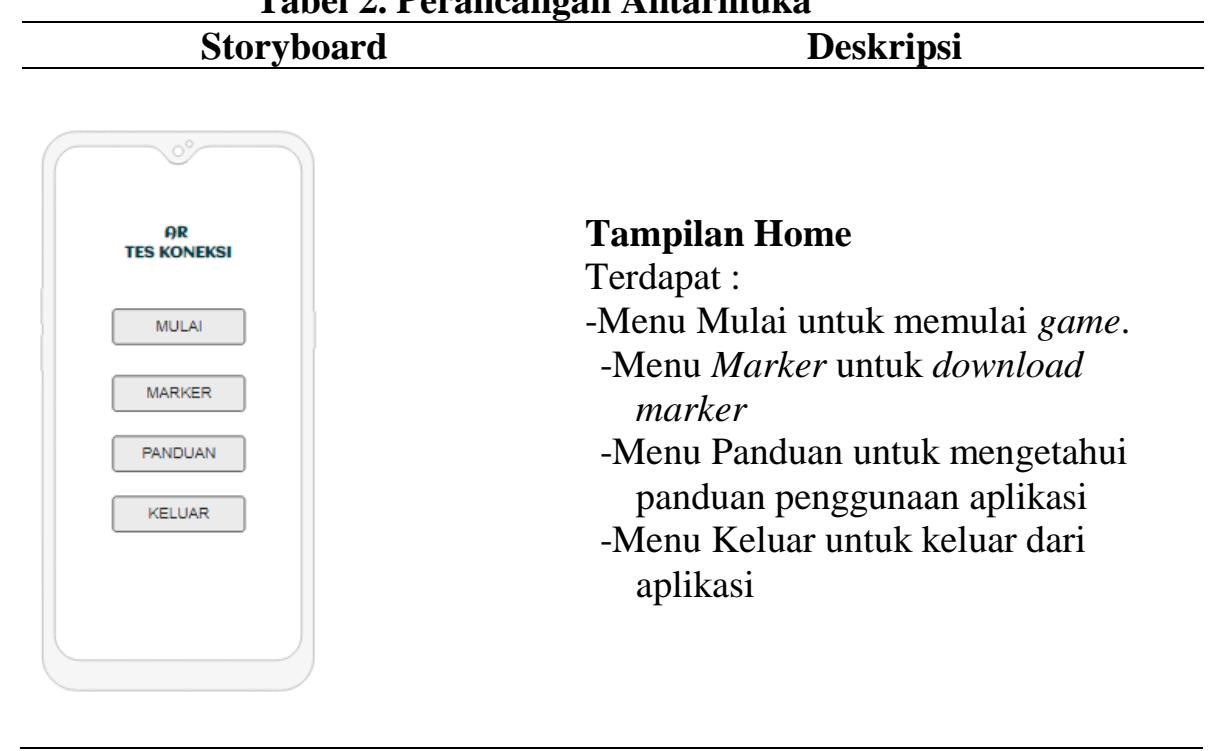




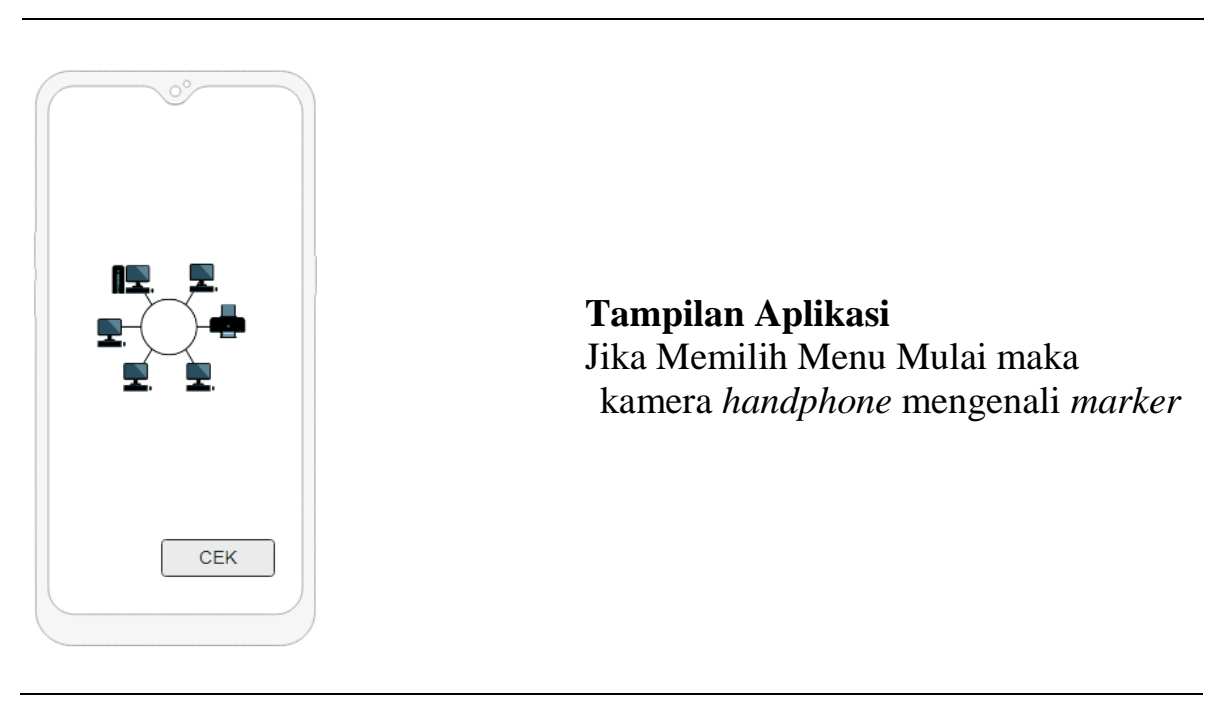

\section{HASIL DAN PEMBAHASAN}

\section{Implementasi Antarmuka}

Tujuan implementasi sistem adalah untuk menjelaskan tentang manual modul kepada semua user yang akan menggunakan sistem. Sehingga user tersebut dapat merespon apa yang ditampilkan di sistem dan memberikan masukan kepada pembuat sistem untuk dilakukan perbaikan agar sistem lebih baik lagi. Pada tahap ini dilakukan penerapan hasil perancangan antarmuka ke dalam sistem yang dibangun dengan menggunakan perangkat lunak yang telah dipaparkan pada sub bab implementasi perangkat lunak.

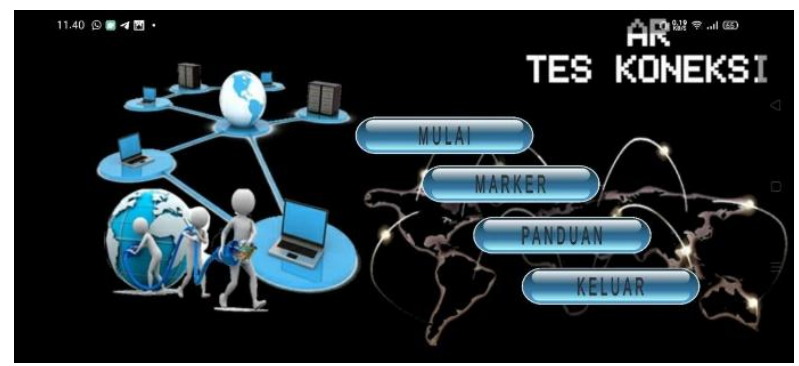

Gambar 2. Tampilan Awal Aplikasi

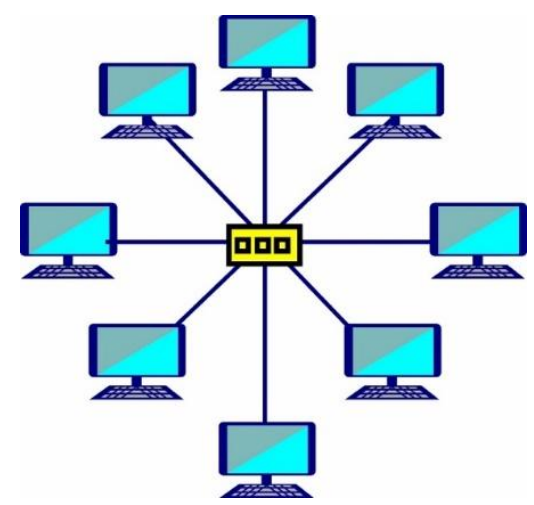

Gambar 3. Tampilan Marker Topologi 


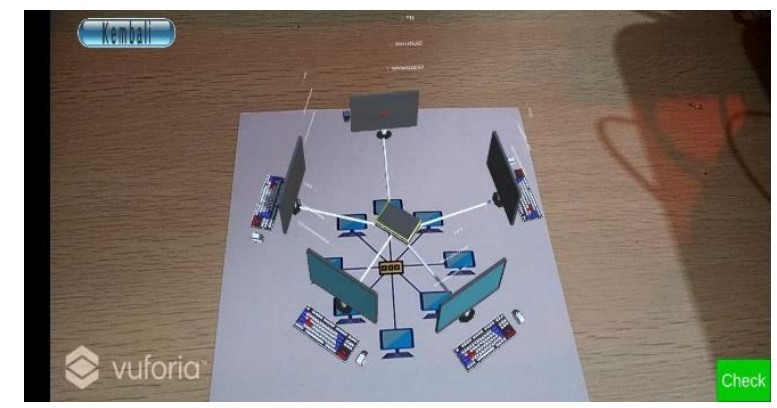

Gambar 4. Tampilan Setting Ip Address

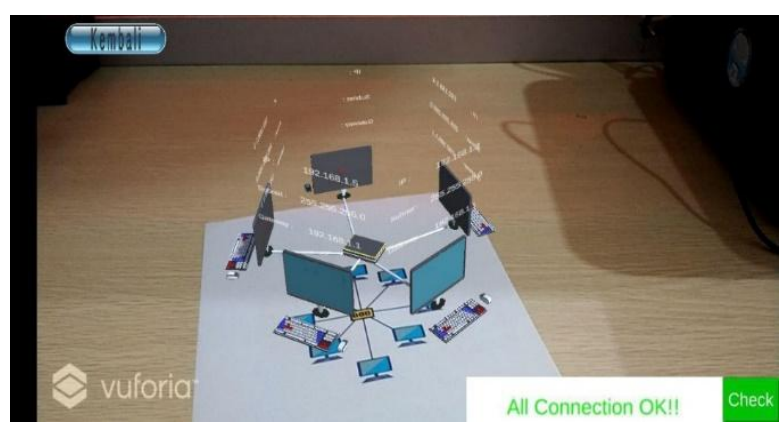

\section{Gambar 5. Tampilan Tes Koneksi Jaringan}

\section{PENGUJIAN}

- Pengujian Perangkat Mobile

Pada pengujian ini dilakukan percobaan pada beberapa perangkat mobile dengan spesifikasi yang berbeda-beda. Hasilnya dapat dilihat pada Tabel 3 dengan keterangan bahwa "terpasang" mengartikan aplikasi terpasang pada perangkat mobile, dan "berjalan" mengartikan aplikasi dapat diimplementasikan pada perangkat mobile. 
Tabel 3. Pengujian Perangkat Mobile

\begin{tabular}{|c|c|c|c|}
\hline NO & $\begin{array}{l}\text { JENIS } \\
\text { MOBILE }\end{array}$ & SPESIFIKASI MOBILE & KETERANGAN \\
\hline \multirow{4}{*}{1} & \multirow{4}{*}{ Realme $5 \mathrm{i}$} & Ram : 4 GB & \multirow{4}{*}{$\begin{array}{l}\text { Aplikasi terpasang } \\
\text { dan berjalan } \\
\text { dengan hasil objek } \\
\text { 3D yang jelas }\end{array}$} \\
\hline & & Kamera : $12 \mathrm{MP}$ & \\
\hline & & Android : Android 9.0 (Pie) & \\
\hline & & $\begin{array}{l}\text { Processor : Octa-core (4x2.0 GHz Kryo } 260 \\
\text { Gold \& 4x1.8 GHz Kryo } 260 \text { Silver) }\end{array}$ & \\
\hline \multirow{4}{*}{2} & \multirow{4}{*}{$\begin{array}{l}\text { Asus } \\
\text { Zenfone } \\
\text { Max (M2) } \\
\text { ZB633KL }\end{array}$} & Ram : 4 GB & \multirow{4}{*}{$\begin{array}{l}\text { Aplikasi terpasang } \\
\text { dan berjalan } \\
\text { dengan hasil objek } \\
\text { 3D yang jelas }\end{array}$} \\
\hline & & Kamera : $13 \mathrm{MP}$ & \\
\hline & & Android : Android 8.1 (Oreo) & \\
\hline & & $\begin{array}{l}\text { Processor : Octa-core ( } 4 \times 1.8 \mathrm{GHz} \text { Kryo } 250 \\
\text { Gold \& 4x1.8 GHz Kryo } 250 \text { Silver) }\end{array}$ & \\
\hline \multirow{4}{*}{3} & \multirow{4}{*}{$\begin{array}{l}\text { Xiaomi } \\
\text { Redmi Y1 } \\
\text { (Note 5A) }\end{array}$} & Ram: 4GB & \multirow{4}{*}{$\begin{array}{l}\text { Aplikasi terpasang } \\
\text { dan berjalan } \\
\text { dengan hasil objek } \\
\text { 3D yang jelas }\end{array}$} \\
\hline & & Kamera : $13 \mathrm{MP}$ & \\
\hline & & Android : Android 7.1.2 (Nougat) & \\
\hline & & Processor: Octa-core $1.4 \mathrm{GHz}$ Cortex-A53 & \\
\hline \multirow{4}{*}{4} & \multirow{4}{*}{$\begin{array}{l}\text { Sony } \\
\text { Xperia Z2 }\end{array}$} & Ram : 3GB RAM & \multirow{4}{*}{$\begin{array}{l}\text { Aplikasi Tidak } \\
\text { Dapat Terpasang }\end{array}$} \\
\hline & & Kamera : $20.7 \mathrm{MP}$ & \\
\hline & & Android : Android 6.0 (Marshmallow) & \\
\hline & & Processor : Quad-core $2.3 \mathrm{GHz}$ Krait 400 & \\
\hline \multirow{4}{*}{5} & \multirow{4}{*}{$\begin{array}{l}\text { Xiaomi } \mathrm{Mi} \\
\mathrm{A} 1 \quad(\mathrm{Mi} \\
5 \mathrm{X})\end{array}$} & Ram : 4GB & \multirow{4}{*}{$\begin{array}{l}\text { Aplikasi terpasang } \\
\text { dan berjalan } \\
\text { dengan hasil objek } \\
\text { 3D yang jelas }\end{array}$} \\
\hline & & Kamera : $12 \mathrm{MP}$ & \\
\hline & & Android : Android 7.1.2 (Nougat) & \\
\hline & & Processor : Octa-core $2.0 \mathrm{GHz}$ Cortex-A53 & \\
\hline
\end{tabular}

Pengujian Perangkat Mobile menjelaskan bahwa tidak semua jenis android yang digunakan dalam pengujian ini dapat menjalankan aplikasi AR. Hanya perangkat yang memiliki spesifikasi minimal menggunakan Android 7.0 Nougat yang dapat terpasang dengan baik.

\section{- Pengujian Marker}

Pada pengujian marker ini dilakukan dengan pengujian jarak minimum menggunakan tiga jenis ukuran marker dan perangkat mobile yang memiliki spesifikasi minimal untuk menjalankan aplikasi ini, yaitu Realme 5i. Hasilnya dapat dilihat pada Tabel 4.2 dimana tanda checklist $(\sqrt{ })$ menjelaskan bahwa marker terdeteksi, yaitu perangkat mobile dapat menampilkan objek 3D dengan 
baik, sedangkan tanda silang $(\times)$ menjelaskan bahwa marker tidak terdeteksi yaitu objek 3D tidak tampil.

Tabel 4. Pengujian Marker

\begin{tabular}{ccccc}
\hline No & Jarak (cm) & $\begin{array}{c}\text { Marker } \\
\mathbf{1 0} \mathbf{~ c m}\end{array}$ & $\begin{array}{c}\text { Maker } \\
\mathbf{1 5} \mathbf{~ c m}\end{array}$ & $\begin{array}{c}\text { Marker } \\
\mathbf{2 0} \mathbf{~ c m}\end{array}$ \\
\hline 1 & 100 & $\mathrm{x}$ & $\sqrt{ }$ & $\mathrm{x}$ \\
\hline 2 & 90 & $\sqrt{ }$ & $\sqrt{ }$ & $\mathrm{x}$ \\
\hline 3 & 80 & $\sqrt{ }$ & $\sqrt{ }$ & $\mathrm{x}$ \\
\hline 4 & 70 & $\sqrt{ }$ & $\sqrt{ }$ & $\sqrt{ }$ \\
\hline 5 & 60 & $\sqrt{ }$ & $\sqrt{ }$ & $\sqrt{ }$ \\
\hline 6 & 50 & $\sqrt{ }$ & $\sqrt{ }$ & $\sqrt{ }$ \\
\hline 7 & 40 & $\sqrt{ }$ & $\sqrt{ }$ & $\sqrt{ }$ \\
\hline 8 & 30 & $\sqrt{ }$ & $\sqrt{ }$ & x \\
\hline 9 & 20 & $\sqrt{ }$ & $\mathrm{x}$ & $\mathrm{x}$ \\
\hline 10 & 10 & $\mathrm{x}$ & $\mathrm{x}$ & $\mathrm{x}$ \\
\hline
\end{tabular}

Tabel menjelaskan bahwa semakin kecil ukuran marker, jarak perangkat kamera mobile semakin dekat untuk mendeteksi marker, dan semakin besar marker yang digunakan maka semakin jauh jarak perangkat kamera mobile dalam mendeteksi marker. Jarak terbaik antara perangkat mobile dalam mendeteksi marker adalah $40 \mathrm{~cm}-70 \mathrm{~cm}$ untuk semua ukuran marker, yaitu ukuran $10 \mathrm{~cm} \mathrm{cm,} 15 \mathrm{~cm}$ dan $20 \mathrm{~cm}$

\section{- Pengujian Black-Box}

Black-Box Testing atau yang sering dikenal dengan sebutan pengujian fungsional merupakan metode pengujian Perangkat Lunak yang digunakan untuk menguji perangkat lunak tanpa mengetahui struktur internal kode atau program. Dalam pengujian ini, tester menyadari apa yang harus dilakukan oleh program tetapi tidak memiliki pengetahuan tentang bagaimana melakukannya.

Pengujian Black-Box dilakukan dengan menjalankan aplikasi dengan maksud menemukan kesalahan serta memeriksa apakah sistem dapat berjalan dengan baik sesuai dengan yang direncanakan. Berikut adalah tabel pengujian Black-Box: 
Tabel 5. Pengujian Black-Box

\begin{tabular}{|c|c|c|c|c|}
\hline No & Pengujian & Aksi & $\begin{array}{c}\text { Hasil Yang } \\
\text { Diharapkan }\end{array}$ & $\begin{array}{c}\text { Hasil } \\
\text { Uji }\end{array}$ \\
\hline 1 & $\begin{array}{c}\text { Tampilan } \\
\text { Menu Utama }\end{array}$ & & $\begin{array}{c}\text { Scene Menu Utama } \\
\text { Muncul }\end{array}$ & Sesuai \\
\hline 2 & Tombol Mulai & Sentuh & $\begin{array}{c}\text { Kamera Terbuka } \\
\text { dan Siap Reindering } \\
\text { Objek }\end{array}$ & Sesuai \\
\hline 3 & $\begin{array}{c}\text { Menampilkan } \\
\text { Objek 3D } \\
\text { Topologi }\end{array}$ & $\begin{array}{l}\text { Mengarahkan } \\
\text { Kamera ke } \\
\text { Marker }\end{array}$ & $\begin{array}{l}\text { Objek 3D Topologi } \\
\text { Ring Muncul }\end{array}$ & Sesuai \\
\hline 4 & $\begin{array}{c}\text { Menampilkan } \\
\text { Objek 3D } \\
\text { Topologi } \\
\end{array}$ & $\begin{array}{c}\text { Mengarahkan } \\
\text { Kamera ke } \\
\text { Marker }\end{array}$ & $\begin{array}{l}\text { Objek 3D Topologi } \\
\text { Bus Muncul }\end{array}$ & Sesuai \\
\hline 5 & $\begin{array}{c}\text { Menampilkan } \\
\text { Objek 3D } \\
\text { Topologi } \\
\end{array}$ & $\begin{array}{c}\text { Mengarahkan } \\
\text { Kamera ke } \\
\text { Marker }\end{array}$ & $\begin{array}{l}\text { Objek 3D Topologi } \\
\text { Star Muncul }\end{array}$ & Sesuai \\
\hline 6 & $\begin{array}{l}\text { Pengisian } \\
\text { Alamat IP }\end{array}$ & $\begin{array}{c}\text { Sentuh Objek } \\
\text { PC } 1 \\
\end{array}$ & Isi Alamat IP & Sesuai \\
\hline 7 & $\begin{array}{l}\text { Pengisian } \\
\text { Alamat IP }\end{array}$ & $\begin{array}{l}\text { Sentuh Objek } \\
\text { PC } 2\end{array}$ & Isi Alamat IP & Sesuai \\
\hline 8 & $\begin{array}{l}\text { Pengisian } \\
\text { Alamat IP }\end{array}$ & $\begin{array}{l}\text { Sentuh Objek } \\
\text { PC } 3 \\
\end{array}$ & Isi Alamat IP & Sesuai \\
\hline 9 & $\begin{array}{l}\text { Pengisian } \\
\text { Alamat IP } \\
\end{array}$ & $\begin{array}{c}\text { Sentuh Objek } \\
\text { PC } 4 \\
\end{array}$ & Isi Alamat IP & Sesuai \\
\hline 10 & $\begin{array}{l}\text { Pengisian } \\
\text { Alamat IP }\end{array}$ & $\begin{array}{l}\text { Sentuh Objek } \\
\text { PC } 5\end{array}$ & Isi Alamat IP & Sesuai \\
\hline 11 & Test Koneksi & $\begin{array}{l}\text { Sentuh tombol } \\
\text { cek }\end{array}$ & $\begin{array}{l}\text { Sistem mengecek } \\
\text { alamat IP }\end{array}$ & Sesuai \\
\hline 12 & $\begin{array}{l}\text { Tombol } \\
\text { Marker }\end{array}$ & $\begin{array}{c}\text { Sentuh tombol } \\
\text { Marker }\end{array}$ & $\begin{array}{c}\text { Menampilkan file } \\
\text { download }\end{array}$ & Sesuai \\
\hline 13 & $\begin{array}{l}\text { Tombol } \\
\text { Panduan }\end{array}$ & $\begin{array}{l}\text { Sentuh tombol } \\
\text { Panduan }\end{array}$ & $\begin{array}{l}\text { Menampilkan } \\
\text { Panduan } \\
\text { Penggunaan } \\
\text { Apikasi }\end{array}$ & Sesuai \\
\hline 14 & Tombol Back & Sentuh & $\begin{array}{c}\text { Kembali ke Menu } \\
\text { Utama }\end{array}$ & Sesuai \\
\hline
\end{tabular}

\section{PENUTUP}

Dari hasil pengujian ini dapat disimpulkan bahwa aplikasi AR pada koneksi jaringan ini:

1. Memproyeksikan objek 3D 3 Topologi dasar Jaringan, yaitu Bus, Ring, dan Star .

2. Jika IP Address yang dimasukkan memiliki kelas yang sama, maka koneksi akan berhasil, namun jika tidak dalam kelas yang sama, maka koneksi tidak berhasil

3. Spesifikasi perangkat mobile yang digunakan menggunakan Android 7.0 Nougat

4. Jarak antara perangkat mobile ke marker adalah $40 \mathrm{~cm}-70 \mathrm{~cm}$

Metode ini dikatakan cukup efektif dalam memberikan informasi kepada pengguna. Hal ini dikarenakan sebagian Objek 3D dari topologi sudah divisualisasikan oleh aplikasi AR ini. 
Beberapa saran dan masukkan yang dapat disampaikan penulis terhadap pembuatan aplikasi Augmented Reality Tes Koneksi ini dimasa yang akan datang adalah antara lain:

1. Aplikasi diharapkan dapat dikembangkan dengan menambahkan panduan dan informasi penggunaan.

2. Aplikasi diharapkan dapat dikembangkan dengan pemodelan yang lebih smooth.

3. Aplikasi diharapkan dapat dikembangkan dengan mengubah tampilan menjadi lebih menarik.

\section{DAFTAR PUSTAKA}

Azuma, Ronald T. August 1997. "A Survey of Augmented Reality". Presence: TeleoperatorsandVirtualEnvironments.

Fadlil, Abdul, dkk. 2017. "Pengembangan Sistem Pengaman Jaringan Komputer Berdasarkan Analisis Forensik Jaringan". Universitas Ahmad Dahlan.

Hanafi, Miftah Rizqi. 2015. "Analisis Dan Perancangan Aplikasi Geometra, Media Pembelajaran Geometri Mata Pelajaran Matematika Berbasis Android Menggunakan Teknologi Augmented Reality".Tugas Akhir Skripsi.Universitas Negeri Yogyakarta.

Harni Kusniyati, Nicky Saputra Pangondian Sitanggang. 2016. Aplikasi Edukasi Budaya Toba Samosir Berbasis Android". Jurnal Teknik Informatika. 9(1): 11.

Hikmaturokhman, Alfin, dkk. 2015. "Implementasi Mobile Augmented Reality 3 Dimensi Pada Petunjuk Praktikum Drive Test”. ST3 Telkom Purwokerto.

Karisman, Aprian, dkk.2019. "Aplikasi Media Pembelajaran Augmented Reality Pada Perangkat Keras Komputer Berbasis Android". Sekolah Tinggi Teknik Multimedia Cendekia Abditama.

Muntahanah, dkk. 2017. "Penerapan Teknologi Augmented Reality Pada Katalog Rumah Berbasis Android (Studi Kasus Pt. Jashando Han Saputra)". Universitas Muhamamadiyah Bengkulu.

Nadira, Zahra, dkk. 2016. "Implementasi Augmented Reality Pada Brosur Teknik Informatika Universitas Tanjungpura Menggunakan Metode Marker”. Universitas Tanjungpura.

Riccitiello, John. 2014. John Riccitiello sets out to identify the engine of growth for Unity Technologies (interview). VentureBeat. Interview with Dean Takahashi. Retrieved January 18, 2015.

Safaat, Nazrudin. 2011. "Android Pemograman Aplikasi Mobile Smartphone Dan Tablet PC Berbasis Android". Informatika, Bandung.

Safaat, Nazruddin. 2012. "Pemrograman Aplikasi Mobile Smartphone dan Tablet PC berbasis Android'. Informatika Bandung: Bandung.

Saputra, Yoga Aprillion. 2014 "Implementasi Augmented Reality (AR) Pada Fosil Purbakala Di Museum Geologi Bandung”. Universitas Komputer Indonesia. 
Sari, Citra Arum. 2018. "Penerapan Augmented Reality dalam Visualisasi Katalog Apartemen Berbasis Android". Universitas Udayana.

Suharso, Aries, Angga Adhi Pramana. 2016. "Media Pembelajaran Perangkat Keras Jaringan Komputer Berbasis Magicbook Augmented Reality". Universitas Singaperbangsa Karawang.

Wasista, Sigit, dkk. 2016. "Aplikasi Augmented Reality Untuk Pengenalan Perangkat Jaringan Komputer Berbasis Android Sebagai Media Pembelajaran Interaktif”. Politeknik Elektronika Negeri Surabaya.

Zianuddin, Zahir, dkk. 2016. "Aplikasi Augmented Reality pada Sistem Informasi Smart Building". Universitas Hasanuddin 